\title{
Outer cores of the terrestrial planets: Eutectic-melt hypothesis
}

\author{
KeISUKe ITo \\ Department of Earth Sciences, Faculty of Science, \\ Kobe University, Nada, Kobe 657, Japan
}

(Received May 18, 1976)

\begin{abstract}
A hypothesis is proposed that outer cores of the terrestrial planets consist of a eutectic melt between the inner core iron and the lower mantle oxide. $\mathrm{MgO}$, a major consituent of the lower mantle, is estimated to be substantially soluble in iron melt at high pressures and high temperatures reached in the outer core. Mars does not have an outer core, and Venus has a much smaller outer core than the Earth. On an assumption that the overall chemistry ( $\mathrm{Fe} / \mathrm{Oxide}$ ratio) is the same among the terrestrial planets except Mercury, or an alternative assumption that the metallic-iron/total-mass ratio increases in the decreasing order of distance from the sun, from 0.20 for Mars to 0.25 for Earth and Venus, the eutectic composition is estimated to be 0.41 by the first assumption or 0.24 by the second one. The Earth, when it was hotter, did not have a solid inner core. When it cooled, iron and oxide coprecipitated from the eutectic melt, iron sank to form the inner core, and oxide floated to form the $\mathrm{D}^{\prime \prime}$ region.
\end{abstract}

\section{INTRODUCTION}

The earth's outer core is widely believed to consist of iron-nickel alloy with substantial amounts of lighter elements such as silicon and sulfur (MACDONALD and KNOPOFF, 1958; RINGwOoD, 1959). This hypothesis requires that the overall compositions of the terrestrial planets are different. For example, the iron/silicate ratio of the earth should be higher than those of Venus and Mars. To avoid this complexity, an alternative hypothesis that the core is made of silicate transformed into the metallic state under pressures has been proposed by RAMSEY (1948).

The phase transition hypothesis is not favored currently because shock wave experiments on silicates have failed to show the insulatorto-metal transition in oxides and silicates. Recently, KawaI and NishiYama (1974) and VERESHCHAGIN et al. (1974) reported insulatorto-metal transitions in $\mathrm{SiO}_{2}, \mathrm{MgO}, \mathrm{FeO}$ and $\mathrm{Al}_{2} \mathrm{O}_{3}$ under hydrostatic pressures above $1 \mathrm{Mb}$. Though their findings are disputable, if they are true the phase transition hypothesis should be re-evaluated. The hypothesis, however, has another serious difficulty that the big density jump of nearly $90 \%$ at the mantle-core boundary is much larger than even the large (about 30\%) density changes of insulator-to-metal transitions.

BULLEN (1973) proposed an alternative hypothesis that the outer core consists of $\mathrm{Fe}_{2} \mathrm{O}$ which is not stable at ordinary pressures but is expected to be stable at pressures reached in the outer core. The $\mathrm{Fe}_{2} \mathrm{O}$ hypothesis avoids the difficulties of the phase-transition hypothesis while retaining the idea that the mantle-core boundary is a pressure-induced phenomenon. The stability of $\mathrm{Fe}_{2} \mathrm{O}$ and its density-pressure relation are quoted by BULLEN to have been suggested by O. E. SorotKIN, but the detail of calculation is not reported. The process of accumulating $\mathrm{Fe}_{2} \mathrm{O}$ in the outer core is neither explained.

In the present paper, an alternative hypothesis that the outer core consists of a eutectic melt between iron (the inner core) and oxide (the lower mantle) is proposed. The eutectic melt hypothesis resembles BULLEN's $\mathrm{Fe}_{2} \mathrm{O}$ hypothesis, $\mathrm{Fe}_{2} \mathrm{O}$ in the latter being replaced by the eutectic melt in the former.

\section{Iron-oxide Systems at Very High Pressures}

It is well established that insulators tend to transform to metals at high pressures. There is a correlation between the transition pressure and the average atomic number of material. The transition pressure is higher for insulators of light elements and their compounds than for 
those of heavy elements and their compounds. An empirical relationship predicts that $\mathrm{MgO}$ may transform to metal at $1 \sim 2 \mathrm{Mb}$ (NEwToN, 1966).

A generalized $P-T$ phase diagram of an insulator illustrating the insulator-to-metal transition and melting curve is shown in Fig. 1. It should be noted that near the triple point where the insulator, metal and liquid coexist, the melting curve of insulator has a negative slope, indicating that the liquid is denser than the solid. If the prediction stated above is true, $\mathrm{MgO}$ may have a liquid phase denser than solid under pressures in the outer core $(>1.3 \mathrm{Mb})$.

At ordinary pressures, iron and an oxide such as $\mathrm{MgO}$ and $\mathrm{FeO}$ are immiscible in the liquid state (Fig. 2-A), because the repulsion force between iron and the oxide is so strong. Thermodynamic property of such a binary system $\mathrm{A}-\mathrm{B}$ is expressed by the regular solution model with a large $W$-term, given by $\frac{\mathrm{z}}{2}\left(V_{\mathrm{AA}}+\right.$ $\left.V_{\mathrm{BB}}-V_{\mathrm{AB}}\right)$. Here, $z$ is the average number of nearest neighbors of $\mathrm{A}$ and $\mathrm{B}$, and $V_{\mathrm{AA}}, V_{\mathrm{BB}}$ $V_{\mathrm{AB}}$ are the interaction energy of the $\mathrm{A}-\mathrm{A}$, $\mathrm{B}-\mathrm{B}$ and $\mathrm{A}-\mathrm{B}$ pairs, respectively. When the repulsion force between $\mathrm{A}$ and $\mathrm{B}$ is large, the interaction energy of the A-B pair is relatively small, resulting in large $W$. When $W$ is large, the solution has large positive deviation from ideality and the two components are immiscible.

It is reasonable to assume that the repulsion force between iron and an oxide decreases at very high pressures where the oxide is about to transform to the metallic state. Weak repulsion forces results in decreasing $W$-term for the iron-oxide solution and thus increasing the

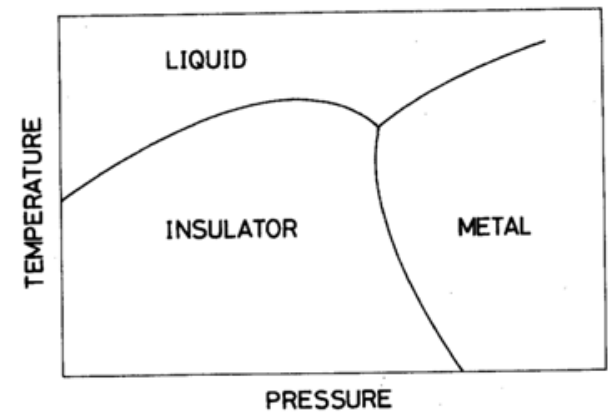

Fig. 1

Fig. 1. A generalized P-T phase diagram for an insulator. Fig. 2. Possible changes of melting relations in the Fe$M O$ system when the pressure increases from $A$ to $D$ (see text for explanation). solubility of oxide in iron melt at very high pressures, as is shown in Fig. 2-B. The system might become completely miscible in the liquid state (Fig. 2-C). At extremely high pressures where the oxide is metallic, the system might be miscible even in the solid state (Fig. 2-D). A speculative trend of phase relationship in a binary system of metal and an oxide as a function of increasing pressure is schematically illustrated in Figs. 2.

For a reaction

$$
\mathrm{MO} \text { (oxide) } \rightarrow(\mathrm{M})_{\text {liquid }}+(\mathrm{O})_{\text {liquid }},
$$

the solubility $(X)$ of $\mathrm{MO}$ in liquid iron is given by the equation

$$
\Delta G=\Delta H-T \Delta S+P \Delta V=-\mathrm{R} T \ln X^{2}
$$

where $\Delta G, \Delta H, \Delta S$, and $\Delta V$ are the changes of Gibbs' free energy, enthalpy, entropy and volume, respectively, for the reaction (1). Since $\Delta S$ is generally positive, the solubility increases as temperature increases. The sign of $\Delta V$ is generally positive at ordinary pressures, but may become negative at high pressures where the melting curve of oxide has a negative slope (see Fig. 1). As $\mathrm{MgO}$ is expected to have a melting curve with negative slope at pressures reached in the outer core, $\Delta V$ may be negative or negligibly small at these pressures. If so, $\mathrm{MgO}$ may be highly soluble in iron melt at high temperatures and pressures in the outer core.

Alder (1966), using the theory of HildEBRAND and SCOTT (1962) of the regular solution model, estimated the solubility of $\mathrm{MgO}$ in
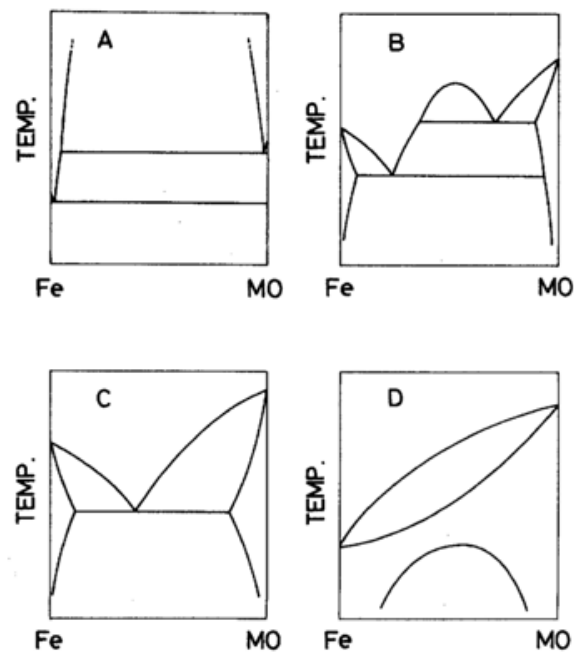

Fig. 2 
liquid iron as about 10 weight per cents at the mantle-core interface condition of $1.35 \mathrm{Mb}$ and $4,400^{\circ} \mathrm{K}$. The estimate may be in error by a factor of more than two, because uncertainties included in the estimation are rather large. If $\mathrm{MgO}$ is about to transform to metallic state under the outer core condition, ALDER's estimate may well be an underestimate.

Another reason to estimate that the solubility of an oxide in iron melt may be large at very high pressures comes from an empirical law found in high-pressure experiments. At high pressures, an element or a compound transforms to a physical state which a heavier element or a compound of heavier elements of the same group posesses at ordinary pressures. The best example may be seen in the group IV elements from $\mathrm{C}$ to $\mathrm{Pb}$. Therefore, iron and iron-oxide which are immiscible at ordinary pressures may become completely miscible in the liquid state at very high pressures as iron and iron-sulfide are miscible in the liquid state at ordinary pressures.

\section{Outer Cores of the Terrestrial Planets}

The terrestrial planets consist of two primary materials, represented by the silicate portion and the iron-nickel portion of meteorites. In the following, the former is denoted by $\mathrm{MO}$ and the latter by Fe. Suppose that the former composes the primary mantle and the latter the primary core. The depth and pressure at the boundary, $\mathrm{P}$, between the primary mantle and core are denoted by $D_{P}$ and $P_{P}$, respectively. The complete differentiation of the primary mantle and core is assumed for the purpose of simplicity and easy understanding, and does not necessarily mean that the terrestrial planets were formed in such a way that iron accreted first in the center and silicates later on the surface.

If the temperature in the primary mantle of a planet is lower than the eutectic temperature of the Fe-MO system (Fig. 3-A), the planet consists of the mantle and a small iron core. The mantle/core mass ratio retains the primary $\mathrm{MO} / \mathrm{Fe}$ ratio. Mars represents the case.

If the temperature reaches the eutectic temperature in the primary mantle at a depth $D_{N}$ and pressure $P_{N}$ (Fig. 3-B), the mantle material existing between $D_{N}$ and $D_{P}$ reacts with a part of the core to form a eutectic liquid in the $\mathrm{Fe}$ MO system at pressures of these depths. The mantle-core boundary shifts from $\mathrm{P}$ to $\mathrm{N}$.

When the eutectic composition is $X_{\mathrm{E}}(\mathrm{MO} /$ $\mathrm{MO}+\mathrm{Fe}$ in weight ratio) and the mass between $\mathrm{N}$ and $\mathrm{P}$ is $m_{\mathrm{NP}}$, the mass of the outer core is given by $m_{\mathrm{NP}} / X_{\mathrm{E}}$. Because $m_{\mathrm{NP}}$ increases with increased size of planet, the proportion of liquid outer core in the total core increases with the size of planet. The Earth, therefore, should have the outer core larger than does Venus.

The chemistry of the outer core may be estimated on an assumption that the overall compositions of the terrestrial planets, Mars, Earth and Venus except Mercury are the same. It follows that

$$
\left(m_{\mathrm{Fe}} / M\right)_{\text {primary }}=\left(m_{\mathrm{C}} / M\right)_{\mathrm{Mars}}
$$

where $M$ is the total mass, $m_{\mathrm{Fe}}$ the mass of primary iron core, and $m_{\mathrm{C}}$ the mass of present core. For Mars with a radius of $3,388 \mathrm{~km}$, we take $\left(m_{\mathrm{C}} / M\right)_{\text {Mars }}=0.20$, using the equations of
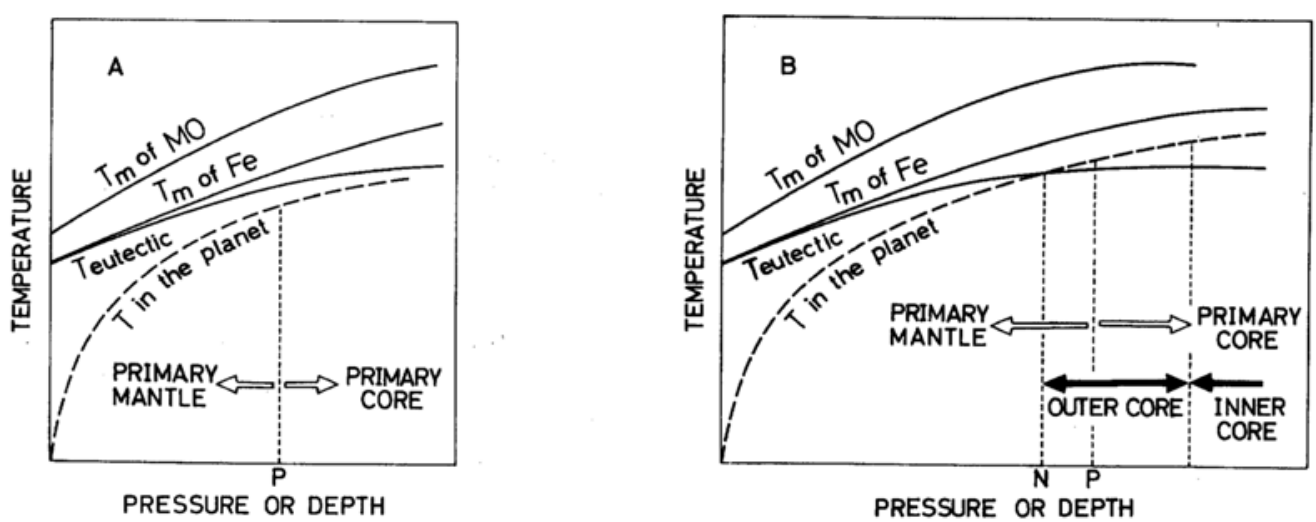

Fig. 3. Melting temperatures of $\mathrm{Fe}, \mathrm{MO}$ and their eutectic composition, and temperature distributions in a planet without an outer core (case A) and a planet with an outer core (case B). 
state for the mantle and core given by KovACH and ANDERSON (1965). Mercury which is situated closest to the sun must have $\left(m_{\mathrm{Fe}} / M\right)_{\text {primary }}$ higher than other terrestrial planets. It is therefore reasonable to assume that the terrestrial planets closer to the sun have $\left(m_{\mathrm{Fe}} / M\right)_{\text {primary }}$ higher than Mars. Then, we have a second alternative assumption that

$$
\left(m_{\mathrm{Fe}} / M\right)_{\text {primary }}>\left(m_{\mathrm{C}} / M\right)_{\mathrm{Mars}},
$$

for Earth and Venus. To see the effect of higher $\left(m_{\mathrm{Fe}} / M\right)_{\text {primary }}$, we tentatively take $\left(m_{\mathrm{Fe}} /\right.$ $M)_{\text {primary }}=0.25$ for Earth and Venus in the second assumption.

For the Earth, we have $\left(m_{\mathrm{C}} / M\right)_{\text {Earth }}=0.325$, $\left(m_{\mathrm{IC}} / M\right)_{\text {Earth }}=0.017$ and $\left(m_{\mathrm{OC}} / M\right)_{\text {Earth }}=0.308$, where $m_{\mathrm{IC}}$ and $m_{\mathrm{OC}}$ are the mass of inner core and that of outer core, respectively. If the outer core is a eutectic melt between $\mathrm{Fe}$ and $\mathrm{MO}$, the eutectic composition is obtained by

$$
\begin{aligned}
X_{\mathrm{E}} & =\frac{m_{\mathrm{C}}-m_{\mathrm{Fe}}}{m_{\mathrm{OC}}} \\
& =\frac{\left(m_{\mathrm{C}} / M\right)_{\mathrm{Earth}}-\left(m_{\mathrm{Fe}} / M\right)_{\text {primary }}}{\left(m_{\mathrm{OC}} / M\right)_{\mathrm{Earth}}} .
\end{aligned}
$$

We obtain

$$
X_{\mathrm{E}}=0.41 \quad \text { if }\left(m_{\mathrm{Fe}} / M\right)_{\text {primary }}=0.20
$$

and $X_{\mathrm{E}}=0.24 \quad$ if $\left(m_{\mathrm{Fe}} / M\right)_{\text {primary }}=0.25$.

For Venus, estimates of $\left(m_{\mathrm{C}} / M\right)$ range from 0.22 to 0.30 . We take $\left(m_{\mathrm{C}} / M\right)_{\text {Venus }}=0.25$, given by LytTLETON (1973). The mass of outer core for Venus may be estimated by

$$
\begin{aligned}
& \left(m_{\mathrm{OC}} / M\right)_{\text {Venus }}= \\
& \quad \frac{\left(m_{\mathrm{C}} / M\right)_{\text {Venus }}-\left(m_{\mathrm{Fe}} / M\right)_{\text {primary }}}{X_{\mathrm{E}}}
\end{aligned}
$$

We obtain

$$
\begin{aligned}
& \left(m_{\mathrm{OC}} / M\right)_{\text {Venus }}=0.12 \\
& \text { or } \quad\left(m_{\mathrm{OC}} / m_{\mathrm{C}}\right)_{\text {Venus }}=0.5 \\
& \text { if }\left(m_{\mathrm{Fe}} / M\right)_{\text {primary }}=0.20 \\
& \text { and }\left(m_{\mathrm{OC}} / m_{\mathrm{C}}\right)_{\text {Venus }}=0.0 \\
& \text { if }\left(m_{\mathrm{Fe}} / M\right)_{\text {primary }}=0.25 \text {. }
\end{aligned}
$$

It is seen that Venus has the outer core much smaller than does the Earth.
At the core-mantle boundaries of Venus and Earth, we have the following estimates; $P_{N}=1.23 \mathrm{Mb}$ and $D_{N}=3,020 \mathrm{~km}$ for Venus (LytTleton, 1973) and $\mathrm{P}_{\mathrm{N}}=1.35 \mathrm{Mb}$ and $\mathrm{D}_{\mathrm{N}}$ $=2,890 \mathrm{~km}$ for the Earth. Since the eutectic temperatures at $1.23 \mathrm{Mb}$ and $1.35 \mathrm{Mb}$ are not much different (see Fig. 3) and $D_{N}$ for Venus and Earth are about the same, the temperature distribution in Venus' interior is similar to that in the Earth.

\section{VELOCITY-DENSITY RELATION}

The estimated composition of eutectic melt in the Fe-MO system ranges from 0.24 to 0.41 in $\mathrm{MO} / \mathrm{MO}+\mathrm{Fe}$ weight ratio. These are higher than $0.14 \sim 0.20$, currently favored amounts of light elements in the Earth's outer core. One of the strongest reasons for the hypothesis that the outer core consists of iron-nickel alloyed with lighter elements such as silicon and sulfur is that the density-velocity relations of such alloys fit well with that of the Earth's outer core.

So-called Birch's law (see, for example, LIEBERMAN and RINGWOOD, 1973), which indicates a systematic relationship among velocity (v)-density $(\rho)$-average atomic weight $(\overline{\mathrm{M}})$, is widely used for estimating the iron content of the Earth's interior. One of his diagrams (BIRCH, 1961) is shown in Fig. 4 which demonstrates the bulk sound velocity $\left(v_{\phi}\right)$ - density relationship for metals. This diagram has been used to suggest that the mantle is composed principally of light elements and the core of elements of the iron-group, because the $v_{\phi}-\rho$ relation for the core is in the region of the iron-group and that for the mantle is in the region of light metals. The $v_{\phi}-\rho$ relation for the core slightly deviates from that of iron, indicating that the core contains some amount of lighter elements. The amount of lighter elements in the outer core is estimated to be $14 \sim 20 \%$ if the element is silicon on the basis of shock wave experiments on solid iron-silicon alloys (BALCHAN and COWAN, 1966).

BIRCH's law as well as BALCHAN and CowAN's estimate are based on experiments for metals in the solid state. It is questionable that the $v_{\phi}-$ $\rho$ systematics obtained for solids may be applicable to the outer core which is liquid. A $v_{\phi}-\rho$ systematics for liquid is poorly known. Velocity-density relations of basaltic melts measured by MURASE and McBIRNEY (1973) are superimposed in Fig. 4. For comparison, $v_{\phi}-\rho$ 


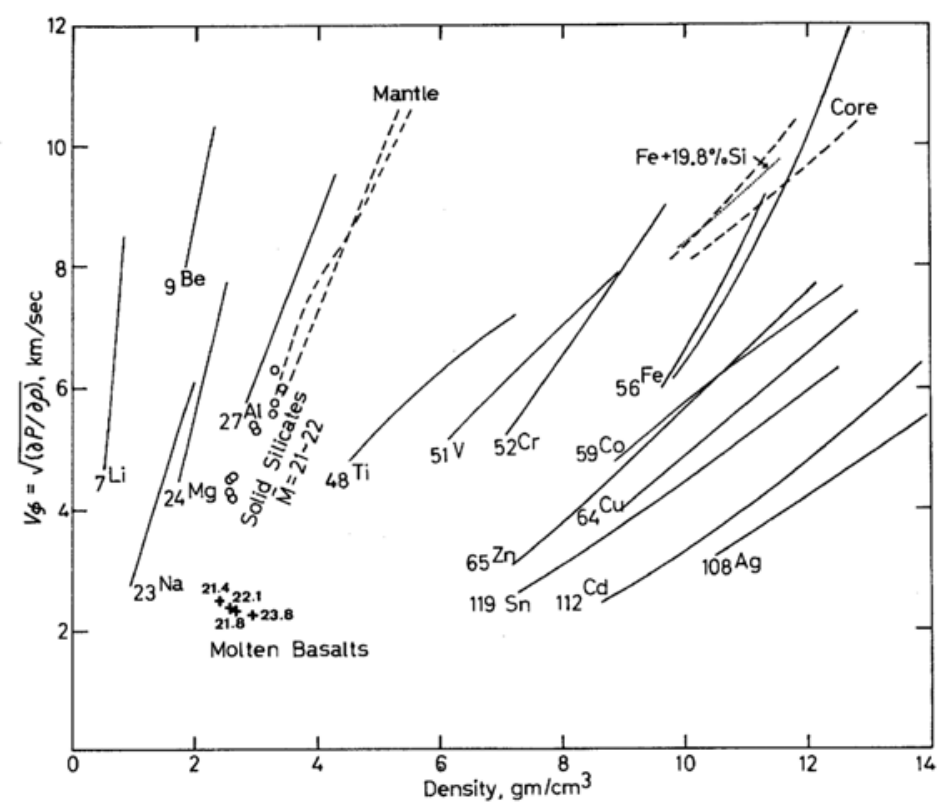

Fig. 4. BIRCH's diagram: bulk sound velocity versus density (BIRCH, 1961). Numbers are the mean atomic weights $(\bar{M})$. Open circles represent data for solid minerals and rocks with $\bar{M}=21 \sim 22$ (ANDERSON, 1967), crosses for molten basalts (MURASE and MCBIRNEY, 1973), and the dotted line for iron alloy with 19.8\% Si at about $3,000^{\circ} \mathrm{K}$ (BALCHAN and COWAN, 1966).

relations for solid rocks and minerals with $\overline{\mathrm{M}}=$ $21 \sim 22$ are taken from ANDERSON (1967) and plotted in the same diagram. It can be seen in Fig. 4 that the $v_{\phi}-\rho$ systematics for oxides is different from that for metals and, to be more important, that the $v_{\phi}-\rho$ relationship for molten basalts with $\overline{\mathrm{M}}=21 \sim 22$ deviates substantially from BIRCH's systematics for solids. Though data are limited, the $v_{\phi}-\rho$ relation for liquids seems to differ from that for solids at constant $\overline{\mathrm{M}}$, deviating towards the low $v_{\phi}$ side. At constant $\rho$, the $v_{\phi}-\overline{\mathrm{M}}$ relation for liquids deviates from that for solids towards the low $\bar{M}$ side. Therefore, the amount of light elements needed to explain the $v_{\phi}-\rho$ relation of the outer core should be higher than $14 \sim 20 \%$, an estimate based on the $v_{\phi}-\rho-\bar{M}$ systematics for solids.

A relatively high amount of light elements $(24 \sim 41 \%)$ in the present hypothesis is not incompatible with the $v_{\phi}-\rho$ relation in the outer core when the deviation of $v_{\phi}-\rho$ systematics for liquids from that for solids is taken into account.

\section{Evolution of the INNER Core and D" Region}

In the present hypothesis, the mantle-core boundary is sensitive to the temperature in the planet. The size of core increases with increased temperature (see Fig. 3). The maximum size is given by

$$
\left(m_{\mathrm{C}} / M\right)_{\max }=\left(m_{\mathrm{Fe}} / M\right)_{\text {primary }} /\left(1-X_{\mathrm{E}}\right) .
$$

When values estimated in the present paper are used, $\left(m_{\mathrm{C}} / M\right)_{\max }$ for the Earth is 0.34 or less. It may be pertinent to the genesis of the $\mathrm{D}^{\prime \prime}$ region at the mantle-core boundary that the maximum size of core is equal to the sum of the $\mathrm{D}^{\prime \prime}$ region and the total core.

If the Earth was hotter at its early stage, the Earth probably had a liquid core having the maximum size given above, without having an inner solid core. When it cooled, both iron and MO coprecipitated from the liquid core having the eutectic composition. The eutectic composition in Fe-MO system, as has been discussed, shifts towards the MO-side as pressure increases. Therefore, iron crystallized at the top of the core, if the core was vertically homogeneous due to convection. The crystallized iron sank to the bottom to form the present inner core. MO, on the other hand, crystallized at the base and floated to the top to form the $\mathrm{D}^{\prime \prime}$ region occurring at the base of the lower mantle with a thickness of about $100 \mathrm{~km}$ at present (ClEARY, 1974). Sinking iron and floating oxide stimulated the convection in the 
outer core needed to generate the Earth's magnetic field.

The mass ratio of $\mathrm{D}^{\prime \prime} /$ Inner Core is about $2 / 3$, fitting the composition of eutectic melt in the Fe-MO system. The coincidences stated above suggest that the central portion including the $\mathrm{D}^{\prime \prime}$ region in the Earth was once a uniform liquid core and the $\mathrm{D}^{\prime \prime}$ region and inner core have grown from the liquid core, representing the light fraction and heavy fraction, respectively, of coprecipitates from the eutectic melt.

\section{REFERENCES}

ALDER, B. J. (1966) Is the mantle soluble in the core? J. Geophys. Res. 71, 4973-4979.

ANDERSON, D. L. (1967) A seismic equation of state. Geophys. J. Roy. Astron. Soc. 13, 9-30.

BALCHAN, A. S. and CowAN, G. R. (1966) Shock compression of two iron-silicon alloys to 2.7 megabars. J. Geophys. Res. 71, 3577-3588.

BIRCH, F. (1961) Composition of the earth's mantle. Geophys. J. Roy. Astron. Soc. 4, 295-311.

BULLEN, K. E. (1973) Cores of the terrestrial planets. Nature 243, 68-70.

Cleary, J. R. (1974) The D" region. Phys. Earth Planet. Inter. 9, 13-27.

KAWAI, N. and NISHIYAMA, A. (1974) Insulatormetal transition in $\mathrm{SiO}_{2}, \mathrm{FeO}$, and $\mathrm{MgO}$. Proc. 4th Intern. Conf. High Pressure, Kyoto, 1974, PhysicoChem. Soc. Japan, 324-326.
KovaCH, R. L. and ANDERSON, D. L. (1962) The interiors of the terrestrial planets. J. Geophys. Res. 70, 2873-2882.

HILDEBRAND, J. H. and SCOTT, R. L. (1962) Regular solutions. 180 pp., Prentice Hall, Englewood Cliffs, N.J.

Lieberman, R. C. and RINGWOod, A. E. (1973) Birch's law and polymorphic phase transformations. $J$. Geophys. Res. 78, 6926-6932.

LYTTLETON, R. A. (1973) Structure of the terrestrial planets. Nature 246, 84-85.

MCDONALD, G. J. F. and KNOPOFF, L. (1958) The chemical composition of the outer core. Geophys. J. Roy. Astron. Soc. 1, 284-297.

Murase, T. and MCBIRNEY, A. R. (1973) Properties of some common igneous rocks and their melts at high temperatures. Geol. Soc. Am. Bull. 84, 3563-3592.

NEWTON, R. C. (1966) The status and future of high static-pressure geophysical research. In Advances in high pressure research Vol 1, ed. R. S. BRADLEY, Academic Press, London, 195-263.

RAMSEY, W. H. (1948) On the constitution of the terrestrial planets. Mon. Not. Roy. Astron. Soc. 108, 406-413.

RINGWOOD, A. E. (1959) On the chemical evolution and densities of the planets. Geochim. Cosmochim. Acta 15, 257-282.

Vereshchagin, L. F., YaKovlev, E. N., VinoGRADOV, B. V., SAKUN, V. P. and STEPANOV, G.N. (1974) Transition of $\mathrm{SiO}_{2}$ to the conducting state. JETP Lett. 20, 215-216. 